International JOURNAL OF MULtidisciplinary REsearch AND ANALysis

ISSN(print): 2643-9840, ISSN(online): 2643-9875

Volume 05 Issue 01 January 2022

DOI: 10.47191/ijmra/v5-i1-19, Impact Factor: 6.072

Page No.- $149-154$

\title{
Correlates of Self Rated Health among Elderly Men and Women from Different Social Classes: A Prospective Study
}

\author{
Subramanyam.V. ${ }^{1}$, Kalavathi, P. ${ }^{2}$, Jamuna.D. ${ }^{3}$ \\ ${ }^{1}$ Department of Psychology, Sampurna Montfort college, Bengaluru, India. \\ ${ }^{2}$ Department of Psychology, Mount Carmel college, Bengaluru, India \\ ${ }^{3}$ Professor of Psychology, Vice Chancellor, Sri Padmavati Mahila Visvavidyalayam (Women's University),Tiruapati.
}

\begin{abstract}
Majority of elderly women experience apprehensions of health and disability especially when they enter 60 plus years. One of the psychological markers of long life is self-rated health which is revealed by western and eastern longitudinal studies on longevous individuals. Self-efficacy beliefs of health as a moderator variable that determine physical wellbeing which in turn leads to mental well-being. Keeping aforementioned in view, data on SRH and its correlates have been identified from a 3-year prospective study carried out on three cohort groups (55-60; 61-65; 66-70). A sample of 480 community dwelling elderly men and women of different social classes (schedule class, schedule tribe \& general open category - non-SC \& ST groups) were drawn from $50-59(\mathrm{~N}=160), 60-69(\mathrm{~N}=160)$, and 70-79 ( $\mathrm{N}=160)$ age groups. Multistage random sampling technique was used to draw subjects from rural areas of Chittoor, Kadapa and Nellore districts. Data pertaining to 480 middle aged and elderly men and women over three consecutive years of testing indicate a significant association between self-rated health with self-regulation, state and trait anxiety, anger, social supports, physical and mental activity, health behavior motivation, health behavior practices and stress, Health care implications are discussed.
\end{abstract}

KEYWORDS: Self-Rated Health, Elderly, Social Classes, and Prospective Study.

\section{INTRODUCTION}

The self-rating of health is an important psychological parameter in the evaluation of health of an elderly person. Such selfassessment of health (SAH) has intrigued because SAH is an important predictor of number of future health outcomes, such as mortality (Benyami \& Idler, 1999), new morbidity (Boswirth \& Schaie, 1997), functional ability (Idler \& Kasl, 1995), health care utilization and hospitalization, recovery from illness, and future physical ratings of health (Maddox \& Doughlass, 1973).

Aging is associated with an increased reliance on health-related and support services. Old age often goes hand in hand with increasingly complex and often-interrelated problems, encompassing physical, psychological, and social health. In $2007,11 \%$ of the population worldwide was 60 years of age or older; this figure is estimated to increase to $22 \%$ by 2050 . Most public policy debates are concerned with the physical issues of aging, whereas social issues, such as social support, tend to be ignored. Older people are faced with greater losses, given fewer social resources and less adequate social support, in both subjectively perceived support and the frequency of contact. Physical activity (PA) also plays a key role in maintaining health and mobility in old age; the evidence for the health benefits of PA is stronger for adults 65 years and older than for any other age group because the consequences of inactivity are more severe for this age group. Furthermore, older people with a high-level social support may achieve the recommended PA more easily than those with lower social support levels, thereby maintaining health and physical functioning (Bohm, Mielke \& da Cruz, 2015).

One of the objectives the study is to assess the correlates of self-rated health (Subjective) among elderly. To realize this an attempt has been made to examine the association of SRH and a set of independent variables viz., self-regulation, state anger, trait anger, anger in and anger control, social supports, health behaviour-practices, health behaviour-motivation, physical, and mental activities and stress included in the study and subjected through correlational analysis in time $e_{1}$, time $_{2}$, and time $_{3}$

Health can be conceptualized and measured in many ways. In many health surveys and questionnaires, respondents are asked to provide a global assessment of their own health. One of the differences between self-ratings of health and physician ratings of health is that the former may embody feelings of psychological well-being, in addition to physical health. Studies reporting SRH 


\section{Correlates of Self Rated Health among Elderly Men and Women from Different Social Classes: A Prospective Study}

among the general population are few. Relative to $\mathrm{SRH}$, some indicators provide direct evidence to the health status of individuals, including previous and current diseases (diagnosed by physicians), and clinical parameters measured in the hospital. These have been termed as "actual" or "objective" health. Some health-related factors, such as demographic characteristics, health history, life habit, life stress and work strain, are closely associated with objective health (Jozefien, Heejung \& Batja, 2015).

\section{Objectives:}

1. To carry out a prospective assessment of self-rated health in a sample of community dwelling elderly men and women from different social classes.

2. To study the how self-rated health is correlated with stress, social supports, health behavior motivation, health behavior practices and physical and mental activities, social supports, anger and state and anxiety of elderly men and women among different social classes, prospectively.

\section{METHOD}

\section{Participants for the study:}

A sample of 480 community dwelling elderly men and women of different social classes (schedule class, schedule tribe $\&$ general open category - non-SC \& ST groups) were drawn from 50-59(N=160), 60-69(N=160), and 70-79 ( $N=160)$ age groups. Multistage random sampling technique was used to draw subjects from rural areas of Chittoor, Kadapa and Nellore districts. The sample was drawn from different age, gender and education (with or without) subgroups of different social classes (viz., schedule tribe, scheduled classes, and general open category groups). The community dwelling elderly men and women with different social classes who are cognitively intact and capable of communication were included in the sample. The sample was tested prospectively (repeatedly) at three different time periods viz., Time-I ( $1^{\text {st }}$ year), Time-II ( $2^{\text {nd }}$ year), and Time-III ( $3^{\text {rd }}$ year). Sample attrition through mortality in the late adult years is a common issue in fresh sample has been recruited as and when it is required a prospective study like this.

\section{MEASURES USED IN THE STUDY}

To collect relevant data as per the objectives, an attempt has been made to select suitable measures. These tools which were selected for purposes of current research were tested afresh to check for their relevance. All the tools were translated into Telugu, the regional language and were administered on a small sample as a tryout. The reliability and validity assessments were carried out for each tool to be used in the present study. The description of details of finalized are given below:

\section{A. Personal Data Form (PDF)}

To seek information on relevant socio-demographic characteristics of the participant, a Personal Data Form (PDF) was used to collect information on participant's age, gender, caste (OBC, SC \& ST source of income (Salary, Pension, property, family help, others) educational level in four categories (viz., no education, can only read and write, primary school, high school education and higher secondary / college level education) ), marital status in terms of never married, married and widowed and living arrangements (with whom the elderly is living at present) were gathered through the PDF. An item of self-rated health used to collect the data on self-rated health from the

\section{B. Life Events Scale (Assessment of Stress):}

The Life Events Scale used in the present study was adopted version of the life events scale with 20 items, in which 15 of them are related to the negative life events (loss of spouse, separation of children, sudden accident etc.) and five item are positive life events (like gaining sudden properties recovering from severe health problem etc.) the scale used here not only indicate the incidence of stress through life events but also measure the intensity of stress, the person experienced on each event, with five point scale rating from no stress at all (1) to severe stress (5). The scale was readopted and standardized by Jamuna and Ramamurti (1999) as part of a major research project on psychological profiles of Long- lived persons, where it covers only ten life events. Higher scores indicate higher intensity of stress and low score indicates low intensity of stress. The scale was administered on a sample of thirty elderly men and women with an interval of 10 days. The test-reliability was 0.86 . State, Trait and Anger Expression Inventory (Assessment Personality):

\section{Spielberger's State-Trait Anger Expression Inventory (STAXI)}

Spielberger's State-Trait Anger Expression Inventory (STAXI) was used to evaluated anger isolated from hostility and aggression, covering the anger's experience and expression. It comprises 44 items to rate the intensity of state - trait anger expression. Internal consistency using the Cronbach's alpha coefficient was 0.84 (Spielberger et al., 1985) on a set of 26 representative items were selected from the original inventory (Jamuna, 1991). The correlation of 0.93 indicated that the shorter version was as good 


\section{Correlates of Self Rated Health among Elderly Men and Women from Different Social Classes: A Prospective Study}

as the original. The test-retest reliability was 0.86 . The inventory covers five areas of hostility viz., state anger, trait anger, anger control, anger in and anger out. High score on this scale is an indication of high state and trait anger.

\section{Measure of Perception of Social Supports Inventory}

For purposes of the present study, perception of social supports was measured by using an inventory which was developed by Jamuna and Ramamurti (1991).

The inventory has satisfactory content validity and temporal reliability. Pearson's ' $r$ ' was 0.93 . A set of 10 representative items were selected from the original inventory (Jamuna \& Ramamurti, 1991) to construct a short form of social supports. The original and its short form were both administrated to 30 community dwelling elderly men and women. The correlation of 0.94 , indicated that the shorter version was as good as the original. The test-retest reliability was 0.91 . Each item has a 5 -point rating scale ranging from good support almost all the time (1) to no support (5). The inventory covers five areas of social supports viz., perception of family supports, financial supports, traditional and custom supports, community supports, health and disability support. High score on this scale is an indication of favorable perception of social supports.

\section{E. Self-Rated Health:}

It was assessed through a single item i.e. How would participants rate his/ her (overall) health at present comparing with the last five years. The subject ranked his perception towards health using a rating scale. The responses for this were rated on a five-point scale ranging from not satisfactory (1) to excellent (or) very satisfactory (5). The test - retest reliability for SRH was found to be 0.76 and 0.89 respectively. Thus, the item to measure subjective (self) rating of physical health was found to be reliable and valid. This was standardized on Indian aged as part of major ICSSR Project (Jamuna, 2014) on Fears, Worry and Anxieties of Elderly. SelfRegulatory Scale

\section{F. Measure of Health Behavior (Health Practices and Motivation towards Health)}

An inventory of 5 items to assess the knowledge of diseases, an inventory of 10 items to assess health practices and an inventory of 7 items to assess the health motivation were administered used to collect the data on health practices and motivation towards health. The reliability of knowledge and attitude of health and diseases and health practices inventories were found to be 0.79 and 0.85 , respectively. The reliability of health motivation was found to be 0.81 (interval 15 days $\mathrm{N}=30$ ). A high score on knowledge of health and diseases, health practices and health motivation, inventories indicate good knowledge of health and diseases, health practices and health motivation towards health, respectively.

\section{Physical and Mental Activity Scale:}

A scale of 10 items to measure the physical and mental activities, were administered to collect the data. reliability and content validity. Each item is enclosed with 5-point rating scale (5 to 1). A score of 5 indicates high activity and a score of (1) indicates low activity. Based on the pilot study results, certain modifications were carried-out in the content and meaning of items. For purpose of present study only 5 items were selected from the scale. The test-retest reliability of this scale was found to be 0.81

\section{Statistical Analysis:}

Person product movement correlation technique was used to analyze the trends as per the objectives of the study.

\section{RESULTS AND DISCUSSION}

The results pertaining to correlational analysis are presented in (table-1). It is clear that the self-rated health (subjective) has been significantly positively correlated with (Subscales of personality), Social supports, health behavior practices, health behavior motivation, and physical mental activities. Only anger control and anger out (Subscale of personality) negatively significantly correlated with self-rated health (subjective).

Table-1: Correlation of Independent Variables and Self-Rated Health (subjective) in Time 1

\begin{tabular}{|c|c|c|c|c|c|c|c|c|c|c|c|}
\hline $\begin{array}{l}\text { Dependent } \\
\text { Variable }\end{array}$ & SRS & TA & SA & Al & $A C$ & AO & SSI & HBP & HBM & PMA & Stress \\
\hline SRH & 0.071@ & $.074^{@}$ & $.082^{@}$ & $-126^{* *}$ & $.190^{* *}$ & $-.232^{* *}$ & $.409^{* *}$ & $.264^{* *}$ & $.040^{@}$ & $.195^{* *}$ & $.021^{@}$ \\
\hline \multicolumn{12}{|c|}{$\begin{array}{l}\text { SRH=Self Rated Health, SRS=Self-Regulation, TA=Trait Anxiety, SA=Sate Anxiety, AN=Anxiety In, AC=Anger Control, } \\
\text { AO=Anger Out, SSI=Social Supports, HBP=Health Behavior Practices, HBM= Health Behavior Motivation, } \\
\text { PMA=Physical and Mental Activity, SRH }(0)=\text { Self Rated Health Objective }\end{array}$} \\
\hline
\end{tabular}




\section{Correlates of Self Rated Health among Elderly Men and Women from Different Social Classes: A Prospective Study}

Elderly supported by family members and other significant others, who have good self-regulation, those who do regular exercise, who do physical and mental exercises and activities and who are motivated to improve their health, were found to have positive perception towards their health irrespective of objective health. Elderly who cannot control anger and express outwardly were found to have negative perception towards their health.

Nextly an attempt was made to examine the association between self-rated health (subjective) and independent variables prospectively on the same sample of 480 elderly men and women, who were tested in the $1^{\text {st }}$ year.

Table-2: Correlation of Self-Rated Health (subjective) and Independent Variables in Time 2

\begin{tabular}{|c|c|c|c|c|c|c|c|c|c|c|c|}
\hline $\begin{array}{l}\text { Dependent } \\
\text { Variable }\end{array}$ & SRS & TA & SA & Al & $A C$ & AO & SSI & HBP & HBM & PMA & Stress \\
\hline SRH & $.260 *$ & $0.071^{@}$ & $.050^{@}$ & $.064^{@}$ & $.019 @$ & $.011^{@}$ & $346^{* *}$ & $.386^{* *}$ & $.179^{* *}$ & $.180^{* *}$ & $-.360^{* *}$ \\
\hline \multicolumn{12}{|c|}{$\begin{array}{l}\text { SRH=Self Rated Health, SRS=Self-Regulation, TA=Trait Anxiety, SA=Sate Anxiety, AN=Anxiety In, AC=Anger } \\
\text { Control, AO=Anger Out, SSI=Social Supports, HBP=Health Behavior Practices, HBM= Health Behavior } \\
\text { Motivation, PMA=Physical and Mental Activity, SRH }(0)=\text { Self Rated Health Objective }\end{array}$} \\
\hline$* p<0.05 ; * * p$ & .01 & Not Sign & & & & & & & & & \\
\hline
\end{tabular}

The results pertaining to correlation analysis are presented in (table 2). It is clear that self-rated health (Subjective) was significantly positively correlated with self-regulation, social supports, health behavior practices, health behavior motivation, physical and mental activities, and stress. Elderly supported by family members and other significant others, those who participate in physical activities and who are motivated to improve their health were found to have positive perceptions towards health and positive self-rated health. The correlates of self-rated health (Subjective) were examined prospectively in third year on the same sample who were tested in $1^{\text {st }}$ and $2^{\text {nd }}$ year.

Table-3: Correlation Between Independent Variables and Self-Rated Health (subjective) in Time 3

\begin{tabular}{|c|c|c|c|c|c|c|c|c|c|c|c|}
\hline $\begin{array}{l}\text { Dependent } \\
\text { Variable }\end{array}$ & SRS & TA & SA & Al & $A C$ & AO & SSI & HBP & HBM & PMA & ress \\
\hline SRH & $.014^{@}$ & $.013^{@}$ & $-.150^{*}$ & $-.115^{*}$ & .086 & $-.115^{*}$ & $.387^{*}$ & .034 & $138^{* *}$ & $.536^{* *}$ & $-.115 * *$ \\
\hline \multicolumn{12}{|c|}{$\begin{array}{l}\text { SRH=Self Rated Health, SRS=Self-Regulation, TA=Trait Anxiety, SA=Sate Anxiety, AN=Anxiety In, AC=Anger } \\
\text { Control, AO=Anger Out, SSI=Social Supports, HBP=Health Behavior Practices, HBM= Health Behavior } \\
\text { Motivation, PMA=Physical and Mental Activity, SRH (O) =Self Rated Health Objective }\end{array}$} \\
\hline \multicolumn{12}{|c|}{${ }^{*} \mathrm{p}<0.05 ;{ }^{* *} \mathrm{p}<0.01 @=$ Not Significant } \\
\hline
\end{tabular}

The results were presented in table -3 , shows that Self Rated Health was significantly positively correlated with, Social support, physical and mental activities, health behavior practices, health behavior motivation. State anger,anger in, anger out, and stress was significantly and negatively correlated with SRH. Elderly who can control anger, supported by family members and other significant others, participate in physical activities, who are motivated to improve their health and who practices health behavior were found to have positive perceptions towards health. Elderly who are anger in vulnerable occasions were found to have poor self-rated health.

The results presented in Table 1 to Table 3 attempted to examine how SRH change or stability prospectively over three time periods (T1, T2, T3). Accordingly in this project on SRH in three successive years $(T 1, T 2, T 3)$ sample of subjects were examined and also assessed in each year i.e., in T1, in T2 and in T3. Also, an attempt was made to examine the psychosocial correlates of SRH in Time 1, Time 2 and Time 3. In Time 1 the correlation results highlighted that motivation to keep health \& fitness, selfregulation behavior, control of anger \& anxiety, good health practices, family supports, social supports were found to be significant correlates of SRH in the elderly men and women. It is obvious that objective health consumes a major chunk of variance, good motivation, regulation of one's health habits and certainly influence one's perception towards health.

Similarly, the same elderly men and women, in Time 2 (Table 2) when they advance in age i.e., in Time 2 self-regulation, social supports, physical and mental activity, health behavior motivation, health practices, anger control were found to be significant correlates of self-rated health. These results also suggest that the social supports do influence perception of health followed by self-regulation, anger control, physical \& mental activity, health behavior motivation, health practices of an individual do play a significant factor one's perception towards health i.e., one's self perception of health. 


\section{Correlates of Self Rated Health among Elderly Men and Women from Different Social Classes: A Prospective Study}

In Time3 (Table 3) only social supports, health behavior motivation, physical and mental activities behavior was seemed to be significant correlates among many psychological variables. To conclude, the variables such as social supports, self-regulation activities, anger control, physical and mental activities, health behavior motivation, health behavior practices with advancing age were found to be critical in influence the self-perception of health. It is reported that personality, self-regulation, social supports, health behavior-practices, health behavior-motivation, physical and mental activity significantly correlate with self- rated health (subjective). As reported in Chapter - II among many health issues in old age, self-rated health is a significant one. Over the decades, continuous debate is going on how to develop positive perception towards health in the elderly. Several factors are suspected to affect self-rated health. These factors could be personal or individual related factors. Brinda, Attermann, Gerdtham and Enemark (2006) reported low income, increasing age, female gender, low social caste, rural residence, absence of morbidity and pension supports were significant correlates of poor SRH. Individuals who never attend school has reported poor self-rated health. The results of the present to same extent agree these explanations. The results show that SRH was better in Time 2 compared to Time 1 and Time 3, which explains that in the first wave the sample objective health was found to be positively associated, whereas with increasing age, certain objective health issues plus signs of ageing may appear influence one's self perception.

Functional status and self-rated health are two important indicators of health in old age. They are also important elements of quality of life and are widely used indicators to calculate healthy life expectancy or disability- free life expectancy. Self-rated health describes how a person perceives his or her own health and is an indicator of well-being (Hoeymans et al. 1997).

Hays et al. (1996) reported that among the elderly, poorer self-rated health correlated with depressive symptomatology, poor functional status, and comorbidity, as well as some socioeconomic factors. Self-rated health was an important factor associated with muscle strength among different age groups. Poor self- rated health has been reported to be associated with being more dependent in daily life activities (Ebly et al. 1996), and it may also worsen the quality of life. There have been many studies that have evaluated self- rated health among the Japanese elderly (Ai and Hoshi 2005). However, few have studied younger (middleaged) generations. The results of the present study are in line with these trends. To improve and maintain self- rated health among community residents, it is important to clarify the health-related factors that could affect self-rated health depending on age, which leads to establish public health strategies for each age group.

In several longitudinal studies, self-rated health has been found to be a good predictor for survival and for future health-even better than a physician's assessment. Self-rated health also corresponds closely with general hospital care, old people's home care and physician visits of people aged 65 or over. The subjective well-being of elderly people is related most strongly to perceived health, which in turn is strongly influenced by objective health assessments (Mitrushina \& Satz, 1991).

José (2010) disclosed that SRH is determined by a large array of factors, such as chronic disease conditions, genetic markers, stress factors, and health behaviors. Joana, Angerika and Penka (2015) stated that socialfactors (education, financial resources and monthly income have direct effect on SRH and these social factors influence the relationships of psychological stress and some behavioural factors to SRH. Borg and cristensen (2000) described that lower the social class, the higher the proportion with deterioration of $\mathrm{SRH}$, Which is contradicted with presented study. The results of the study are in agreement with the findings of some studies carried out. Number of studies reported that a social gradient with regard to SRH and changes in SRH over time. The associations between social class and SRH remained statistically significant due to work environment and life style factors. According to Anatharaman (1981) older people, SRH correlated highly with social participation activity and personal attitudes, which is similar to present study findings. There is consistent association between personality factors and self-perceived health. Evidence suggests that personality characteristics such as hostility operate through risky behaviors are associated with health perception. The present study results correlated with the above study. Alos it was found that social supports were significantly correlated with SRH. Mossey and Shapiro (1982) declared self-regulation could contribute to positive perception towards health. It was reported that Health behaviors, physical and mental activity affected positively the Self Rated Health in elderly. Loeb (2004) suggested that promoting self-motivation might increase older men's perceptions of health and well-being.

Therefore, it suggests that these three variables viz., social supports, self-regulation behavior, physical and mental activities, practices, motivation to improve health, and anger management are to be manipulated in health intervention strategies to inculcate positive perception towards health and overcome apprehension of negative thoughts towards health. Since SRH seems to be a critical factor in health and has survival value the outcome of the study would certainly provide certain inputs to promote healthy and active aging. Thus, SRH can serve as a global measure of health status not only in elderly population but also in younger population. 


\section{REFERENCES}

1) Af Sillsn, U., Nilsson J.A., Mansson, N.O., \& Nilsson, P.M. (2005). Self-rated health in relation to age and gender: Influence on mortality risk in the Malmo Preventive Project. Scandinavian Journal of Public Health, 33, 183-89.

2) Aging, 3, 73-77

3) Ai, B. \& Hoshi, T. (2005) A study on the availability of subjective health indices for the aged: focus on Japanese and Chinese studies. Nippon Koshu Eisei Zasshi, 52, 841-852. (in Japanese with English abstract).

4) Anantharaman, R.N. (1981). Physical health and adjustment in old age.

5) Benyamini, Y. \& Idler, E.L. (1999). Community studies reporting association between self-rated health and mortality: Additional studies, 1995 - 1998. Research on Aging, 21(4), 392-401.

6) Bohm, A.W., Mielke, G.I. \& da, Cruz, M.F., Ramirez, V.V., Wehrmesister,

7) Bosewirth, H.B. \& Schaie, K.W. (1997). The relationship of social environment, social networks and health outcomes in the Seattle Longitudinal Study: Two analytical approaches. Journal of Gerontology: Series B, Psychological Sciences and social Sciences, 52(5), 197-205.

8) Brindaa, I.E.M., Attermann, J., Gerdthamb, U.G., \& Enemarkcd, U. (2016). Socio-economic inequalities in health and health service use among older adults in India: results from the who study on global ageing and adult health survey. Public Health 141, 32-41.

9) Leersnyder, Jozefien \& Kim, Heejung \& Mesquita, Batja. (2015). Feeling right is feeling good: Psychological well-being and emotional fit with culture in autonomy- versus relatedness-promoting situations.. Frontiers in Psychology. 6. 1-12. 10.3389/fpsyg.2015.00630. Jamuna, D. \& Ramamurti, P.V. (1991). Social Supports Inventory for the elderly. Journal of Psychological Researches, 35, 133 - 136.

10) Ebly, E.M., Hogan, D.B. \& Fung, T.S. (1996) Correlates of self-rated health in persons aged 85 and over: results from the Canadian Study of Health and Aging. Canandian Journal of Public Health, 87, 28-31.

11) F.C. (2015). Social support and leisure-time physical activity among the elderly: A population-based study. Journal of Physical Activity Health, 13(6):599-605.

12) Hays, J.C., Schoenfeld, D.E. \& Blazer, D.G., (1996) Determi-nants of poor self-rated health in late life. American Journal of Geriatric Psychiatry, 4, 188-196.

13) Hoeymans, N., Feskens, E.J., van den Bos, G.A., \& Kromhout, D. (1997) Age, time, and cohort effects on functional status and self-rated health in elderly men. American Journal of Public Health, 87, 1620-1625.

14) Idler, E.L. \& Kasi, S. (1995). Self-ratings of health: Do they also predict change in functional ability? Journal of Gerontology: Social Sciences, 50B, S344 - S353.

15) Jamuna, D. \& Ramamurti, P.V. (1991). Social Supports Inventory for the elderly. Journal of Psychological Researches, 35, $133-136$.

16) Joana Simeonova., Angelika Velkova \& Penka Kostadinova (2015). Social characteristics and their effect on self-rated health in persons over 18 years of age. Scripta Scientifica Salutis Publicae, 1(1), 15-20.

17) L. Borg,Jytte Molin Christensen, Jesper Kristiansen, Niels Henrik Nielsen, Torkil ,Menné \& Lars K. Poulsen (2000).Archives of Dermatological Research volume 292, pages285-291.

18) Loeb, S.J. (2004). Older men's health: motivation, self-ratings, and behaviors.

19) Maddox, G.L. \& Douglass, E.B. (1973). Self-assessment of health: A longitudinal study of elderly subjects. Journal of Health and Social Behaviour, 14, 87- 93.

20) Markides, K.S., Lee, D.J,. \& Ray, L.A. (1993). Physicians' ratings of health in middle and old age: a cautionary note. Journal of Gerontology, 48, 24-27.

21) McDonough, P., \& Walters, V. (2001). Gender and health: Reassessing patterns and explanations. Social Science \& Medicine, 52, 547-559.

22) Mitrushina MN, Satz P.(1991). Correlates of self-rated health in the elderly. NursingResearch, 53(3), 198-206.

23) Mossey, J.M. \& Shapiro, E. (1982). Self-rated health: A predictor of mortality among the elderly. American Journal of Public Health, 72, 800 - 808.

24) Spielberger, C., Johnson, E.H., Russell, S.F., Crane, R.J., Jacobs, GA. \& Worden, T.J.(1985). The experience and expression of anger: Construction and validation of an anger expression scale. In M. Chesney \& R. Rosenman (Eds.) Anger, hostility in cardiovascular and behavioural disorders, (5 - 30). Newyork: McGraw-Hill.

25) Wong, M., Yu, R. \& Woo, J. (2017). Effects of Perceived Neighbourhood Environments on Self-Rated Health among Community-Dwelling Older Chinese. International Journal of Environmental Research Public Health, 14(6), 614. 